\title{
Foeto-Maternal Outcome of Obstructed Labour in a Tertiary Care Hospital of Kolkata
}

\author{
Mihir Kumar Sarkar ${ }^{1}$, Arindam Halder ${ }^{2}$ \\ ${ }^{1}$ Department of Obstetrics and Gynaecology, CRSS, Kolkata, West Bengal, India. \\ ${ }^{2}$ Department of Obstetrics and Gynaecology, CRSS, Kolkata, West Bengal, India.
}

\section{ABSTRACT}

\section{BACKGROUND}

Obstructed labour is the situation where in spite of adequate uterine contraction the progressive decent of presenting part is arrested due to mechanical obstruction. Obstructed labour contributes to around eight percent of maternal deaths in India. It is also one of the leading causes of perinatal morbidity and mortality in developing countries. We wanted to study the risk factors and fetomaternal outcome in obstructed labour at Chittaranjan Seva Sadan College of Obstetrics, Gynaecology and Child Health. This will help us to assess obstetric near miss cases and to develop strategies to decrease the complications arising from obstructed labour.

\section{METHODS}

This was a three year retrospective observational study conducted by reviewing the records of obstructed labour during the period April 2014 - March 2017. The study was approved by Institutional Ethics Committee. All the mothers who were admitted in the labour room with signs and symptoms of obstructed labour were included in this study. All the relevant information such as age, parity, socioeconomic status, risk factors, complications, mode of delivery, and fetomaternal outcome were collected.

\section{RESULTS}

There were 219 cases of obstructed labour among a total of 23,815 deliveries. Most common cause for obstructed labour was cephalopelvic disproportion (77\%) followed by malposition/malpresentation (17.3\%). Majority of the patients (69.2\%) belonged to poor socioeconomic group. Sepsis (10.6\%) and pyrexia (9.6\%) were the common complications. Neonatal mortality was $30.8 \%$ and maternal morbidity was $5.8 \%$.

\section{CONCLUSIONS}

Lack of health education, antenatal care, low socioeconomic condition, poor referral system and demographic factors are important contributory factors leading to adverse outcome of obstructed labour. This can be sorted out by proper antenatal care, improving health care delivery system and by timely referral of cases according to partograph monitoring.

\section{KEY WORDS}

Obstructed Labour, Maternal Morbidity, Cephalopelvic Disproportion, Partograph
Corresponding Author:

Dr. Arindam Halder,

Suravi,

Udayan Housing Complex,

Pratapgarh,

Narendrapour,

Kolkata-700103, West Bengal, India.

E-mail: halderarindam1978@gmail.com

DOI: $10.14260 / j e m d s / 2020 / 219$

Financial or Other Competing Interests: None.

How to Cite This Article:

Sarkar MK, Halder A. Foeto-maternal outcome of obstructed labour in a tertiary care hospital of Kolkata. J. Evolution Med. Dent. Sci. 2020;9(13):1019-1021, DOI: 10.14260/jemds/2020/219

Submission 26-01-2019,

Peer Review 10-03-2020,

Acceptance 16-03-2020,

Published 30-03-2020.

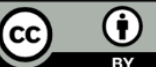




\section{BACKGROUND}

Maternal health is the basic human right of every mother. Maternal mortality has declined in the past 50 years but still the maternal mortality and morbidity in developing countries is higher than developed countries. In India, two-third of the maternal morbidity is due to five main causes-haemorrhage, sepsis, hypertensive disorders, abortion and obstructed labour. This is also a cause of near miss in obstetrics. A maternal near miss is defined as the event where a pregnant woman nearly survived from the complications of pregnancy. Obstructed labour is one of the preventable cause of poor fetomaternal outcome. Obstructed labour is defined as the inability of the passenger (foetus) to progress through the passage (birth canal) despite of strong uterine contractions. ${ }^{2}$ Incidence of obstructed labour is between 0.56 to $1.89 \%$ of all the deliveries in referral hospitals of India. ${ }^{3}$ Still most of the cases of obstructed labour occurred in unbooked cases.

Cephalopelvic disproportion, malpresentation and malposition are important contributing factors. ${ }^{4}$ These factors can be diagnosed in first and second stage of labour with good knowledge of pelvic assessment and partogram. This can be ensured by improving our health care system and ensuring access to the skilled birth attendants during delivery so that they can identify the risk factors and timely manage the complications. ${ }^{5}$ Obstructed labour causes significant short and long term maternal morbidity leading to sepsis, rupture uterus, vesico-vaginal fistula and depression. Fetal asphyxia and fetal death from asphyxia are also common. In primigravida, uterine contractions ceases during progress to obstructed labour whereas multigravida responds with hypertonic uterine contractions till rupture occurs. ${ }^{6}$

Caesarean section remains the mainstay of treatment in obstructed labour in modern era. This decreases the incidence of shock, haemorrhage and trauma of destructive operations. Instrumental vaginal delivery (forceps and ventouse) can be done in case of foetal malposition, soft tissue obstruction or poor bearing down efforts by the mother due to analgesia. Still the final decision depends upon the good judgement and skill of the obstetrician. ${ }^{7}$ Better the antenatal care and intranatal care, lesser will be the incidence of obstructed labour. Contracted pelvis, cephalopelvic disproportion and malpresentation can be detected by trained birth attendants and morbidity could be prevented by timely referral to a tertiary care hospital.

Knowledge of partogram during intrapartum period also aids in early detection and timely intervention before labour becomes obstructed. ${ }^{8}$ The objective of this study was to study the risk factors and fetomaternal outcome in obstructed labour at Chittaranjan Seva Sadan College of Obstetrics, Gynaecology and Child Health Kolkata. This will help us to assess obstetric near miss and to develop strategies to decrease the complications resulting from obstructed labour.

\section{METHODS}

This is a retrospective study done in the Department of Obstetrics and Gynaecology for a period of three year between April 2014 to March 2017. The study was approved by Institutional Ethics Committee. All the mothers who were admitted in the labour room with signs and symptoms of obstructed labour or who developed features of obstruction during the labour were included in the study. Records were checked and reviewed retrospectively to gather information about mothers who admitted for obstructed labour or who developed signs of obstructed labour in due course of time. All the relevant information such as age, parity, socioeconomic status, risk factors, complications, mode of delivery and fetomaternal outcome were collected.

The hospital data and detailed notes were reviewed for obstructed labour. The classical definition was followed for obstructed labour which is defined as failure of descent of the foetal presenting part for mechanical reasons in spite of adequate uterine contractions. ${ }^{8}$ The notes were studied for signs of complications like maternal dehydration, pyrexia, sepsis, rupture, postpartum haemorrhage and urological complications. Maternal mortality as a result of obstructed labour was noted. Mode of delivery and foetal outcome was noted. We came across a very negligible numbers of case sheet with incomplete data entry.

\section{Statistical Analysis}

Data analysis were carried out using Statistical Product Services Solution ((SPSS) IBM version 21.0. Frequency data across categories were compared using Chi-square/Fisher exact test as appropriate. Bivariate correlation followed by multiple linear regression analysis was carried out to find out significant risk factors that influence the fetomaternal outcome. A probability level of $\mathrm{P}<0.05$ was considered for statistical significance.

\section{RESULTS}

In our study, there were 219 cases of obstructed labour in three year out of 23815 deliveries. The percentage of obstructed labour in our hospital was around $1 \%$ per year. Maximum cases occurred in the age group $21-25$ years (43.84\%).

\begin{tabular}{|ccc|}
\hline Age in Years & No. of Cases / Year & \%age of Cases / Year \\
$<20$ & 12 & 16.44 \\
$21-25$ & 32 & 43.84 \\
$26-30$ & 18 & 24.66 \\
$>30$ & 11 & 15.07 \\
\multicolumn{3}{|c}{ Table 1. Age Distribution } \\
\hline
\end{tabular}

\begin{tabular}{|ccc|}
\hline Parity & No. of Cases / Year & \%age of Cases / Year \\
Primigravida & 36 & 49.32 \\
Multigravida $(<3)$ & 21 & 28.77 \\
Grand multiparas $(>3)$ & 16 & 21.92 \\
\multicolumn{2}{|c|}{ Table 2. Parity and Number of Cases } \\
\hline
\end{tabular}

\begin{tabular}{|ccc|}
\hline Booked/Emergency & No. of Cases / Year & \%age of Cases / Year \\
Booked & 31 & 42.47 \\
Emergency & 42 & 57.53 \\
\multicolumn{2}{|c}{ Table 3. Booked and Unbooked Cases } \\
\hline \multicolumn{2}{|c}{}
\end{tabular}

\begin{tabular}{|ccc|}
\hline Causes & No. Cases / Year & \%age of Cases / Year \\
CPD & 14 & 17.3 \\
Malpresentation & 57 & 77 \\
Others & 12 & 15.7 \\
& Table 4. Causes of Obstruction \\
\hline
\end{tabular}




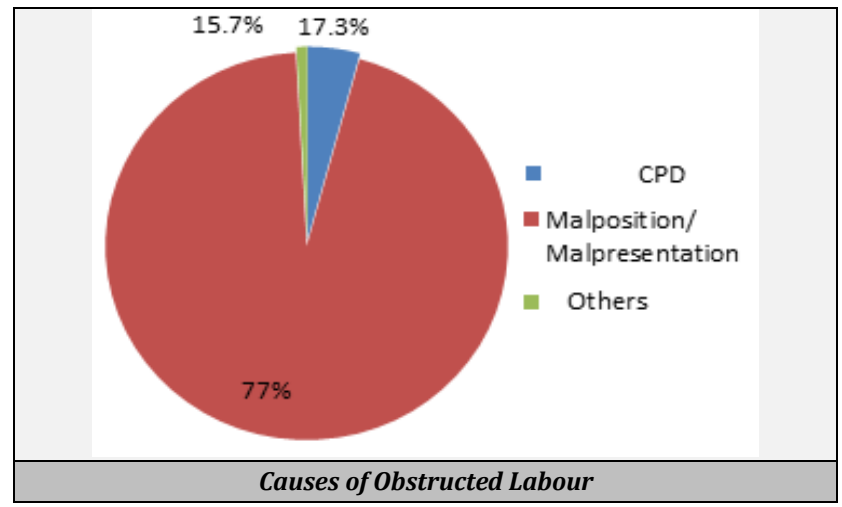

\section{DISCUSSION}

Obstructed labour is still an obstetrician's nightmare and still a prevalent health problem. It is one of the preventable cause of maternal morbidity and mortality. The incidence and complication vary in different countries. The incidence of obstructed labour was $2.73 \%$ in our study which corresponds to the study done by Ikojo et al (2.7\%) and Amanuel Gessessew et al (3.3\%). The incidence of obstructed labour was lower in studies by Adhikari et al (0.56\%). ${ }^{8}$ The incidence was higher in studies done at Jimma hospital Ethiopia (7\%). The relatively high incidence in our hospital was mostly due to poor health care delivery at peripheral health centre and delayed referral of mismanaged cases to a tertiary health centre. Majority of the women in this study were of poor socioeconomic status $(69.2 \%)$ which reflects the poverty, illiteracy and lack of emergency obstetric care in rural areas. Majority of cases were unbooked. $73.1 \%$ from rural and $26.9 \%$ from urban areas which indicates unskilled birth attendants and poor referral system.

Incidence of obstructed labour was $46.1 \%$ in primigravida in our study. This is similar to the studies done by Shagufta 46 , $15 \%$ and Ara et al ${ }^{9} 40.8 \%$. This high incidence is due to poor knowledge of pelvic assessment. Choudhury et al ${ }^{10}$ reported maternal educational status as a predictor of her reproductive health. CPD accounts for $77 \%$ cases of obstructed labour followed by malposition $17.3 \%$. This is comparable to the study done by Shagufta et al where CPD accounts for $87.18 \%$. The common maternal complications were rupture of the uterus $(17.3 \%)$, postpartum haemorrhage $(13.5 \%)$ and hematuria $(8 \%)$. The commonest mode of delivery was by caesarean section as safe obstetric practice in modern era. The most common cause of neonatal morbidity was asphyxia neonatorum $7.69 \%$. The maternal morbidity was is higher than those reported by Adhikari et al (2.04\%) and Nwoguijkojoet al (3.3\%). ${ }^{6}$ Higher morbidity rates in our study may be due to late recognition and referral of unbooked cases in a poor condition. Perinatal mortality was $30.4 \%$ in our study which corresponds to the study of Daffalah et al. ${ }^{11}$ Long term maternal complication was vesico-vaginal fistula reported in two cases. They mostly contributed to maternal morbidity.

\section{CONCLUSIONS}

Obstructed labour is still a major cause of maternal and perinatal morbidity and mortality in developing countries and accounts for approximately eight percent of maternal deaths globally. World Health Organization has called obstructed labour "the most disabling of all maternal conditions," by contributing to $2-8 \%$ of global maternal mortality and complicating $3-6 \%$ of deliveries. The lack of health education, unawareness and importance of antenatal care, low socioeconomic condition, undue interference before referral, late admission were important contributory factors.

The WHO quality of care vision sees a future where "every mother and newborn receive quality care throughout pregnancy, childbirth and postnatal period". This vision is in alignment with two complementary global action agendas conceptualized by WHO and partners in 2013-14 - "Strategies toward Ending Preventable Maternal Mortality (EPMM)" and "Every Newborn Action Plan (ENAP)". This includes proper antenatal and intranatal care, health education, early detection of high-risk cases. Timely referral can prevent the hazards of obstructed labour. High quality care around the time of childbirth makes an improvement. The standards cover routine care and management of complications occurring for women and their babies during labour, childbirth and the early postnatal period.

\section{REFERENCES}

[1] Alkire BC, Vincent JR, Burns CT, et al. Obstructed labor and caesarean delivery: the cost and benefit of surgical intervention. PLoS One 2012;7(4):e34595.

[2] Konje JC, Ladipo OA. Nutrition and obstructed labor. Am J Clin Nutr 2000;72(Suppl 1):291S-7S.

[3] Qureshi RN. Emergency obstetric care. A manual for physicians. J Rep Health 2002: p. 53-9.

[4] Hofmeyr GJ, Say L, Gulmezoglu AM. WHO systematic review of maternal mortality and morbidity: the prevalence of uterine rupture. BJOG 2005,112(9):1221-8.

[5] Omole-Ohonsi A, Ashimi A0. Obstructed labour- a six year review in Aminu Kano teaching hospital, Kano, Nigeria. AJOL 2007;51(4):28843.

[6] Nwogu-lkojo EE, Nweze SO, Ezegwui HU. Obstructed labour in Enugu, Nigeria. J Obstet Gynaecol 2008;28(6):596-9.

[7] Meiah GS, EL-Nafaty AU, Massa AA, et al. Obstructed labour: A public health problem in Gombe, Gombe State, Nigeria. J Obstet Gynaecol 2003;23(4):369-73.

[8] Adhikari SM, Dasgupta M, Sanghamita M. Management of obstructed labour: a retrospective study. J Obstet Gynecol India 2005;55(1):48-51.

[9] Ara A. Outcome of obstructed labour. Int J Gynaec Obstet Original 2011;18(3).

[10] Chowdhury ME, Botlero R, Koblinsky M, et al. Determinants of reduction in maternal mortality in Matlab, Bangladesh: a 30-year cohort study. The Lancet 2007;370(9595):1320-8.

[11] Dafallah SE, Ambago J, EI-Agib F. Obstructed labor m a teaching hospital in Sudan. Saudi Med J 2003;24(10):1102-4. 